\title{
LEIPOLDT IN 1980*)
}

H.M. Viljoen, Dept. Afrikaans-Nederlands, P.U. vir C.H.O.

(Bystand van die Sentrum vir Afrikaans van die RGN in verband met die verkryging van bronnemateriaal word met dank erken)

Oor Leipoldt se veelsydigheid hoef daar nie veel gesê te word nie. Hy was digter, dramaturg, romanskrywer, joernalis, geneesheer, kos- en wynkenner, filantroop, wêreldburger, maar bly tog vir ons in die eerste plek digter. Ons beeld van Leipoldt so oeuvre kan verander - daar is vanjaar al twee "nuwe" werke van hom ontdek maar as daar iets van Leipoldt behoue sal bly, sal dit eerder sy poësie as sy drama, prosa, joernalistieke werk of kookboeke wees; so lyk dit altans op die oomblik. Daarom beperk ek my tot sy poësie en sal ek nie probeer om u totaalbeeld van sy ryk maar erg ongelyke oeuvre te gee nie.

Die probleem met baie van Leipoldt se gedigte deesdae is dat ons dit te goed ken. As ons eers begin met

Jou oë is nat met die trane van gister; Jou siel is gemartel, detr smarte gepla;

Van vrede en pret was jy vroeër 'n verkwister;

En nou, wat bly oor van jou rykdomme? Ja,

skakel 'n deel van ons brein outomaties af. Ek moet dus vanaand probeer om deur daardie outomatisme te breek en $u$ weer vars en nuut na Leipoldt te laat kyk.

Dit kan mens op verskeie maniere doen. Jy kan Leipoldt gaan moderniseer. Dit is betreklik maklik. Jy maak van hom 'n Ingrid Jonker of 'n Antjie Krog, deel van die kultus van die "blootsvoet kind" (Cloete, 1900, p. 150), die spontane, die kinderlike, die naiewe in die poësie. Jy kan tot selfs van hom 'n surrealis maak. Jy kan van hom 'n versetsdigter maak - iemand wat skree teen ontkenning van menswaardigheid, wat staan vir die regte van die swakkeling en die onderdrukte -

* Rede by geleentheid van 'n Leipoldt-aand, gereel deur die Potchefstroomse Werkgemeenskap van die Suid-Afrikaanse Akademie vir Wetenskap en Kuns en die departemente Afrikaans- Nederlands en Spraakleer en Drama van die PU vir CHO op 15 September 1980. 
totdat jy hom naderhand saam met Breytenbach in die tronk wil gaan stop. Jy kan hom homoseksueel verklaar. Jy kan hom die skrywer van gewilde luisterliedjies maak en Laurika Rauch dit laat sing. Daarvoor voel ek my 'n bietjie swak toegerus. Jy kan hom 'n aktuele digter maak, want Leipoldt is ook oorlogsdigter, en as mens sy gedigte op die grens in die natuur lees tussen klippe waarop daar regte egte koggelmannetjies kom om fees te vier, kry dit 'n dimensie wat ek nie vanaand vir $u$ hier ver verwyderd van die oorlog en die natuur kan herskep nie.

Hierdie maniere voel nie heeltemal gepas nie. Hulle is historisties. Maar ongelukkig, al is hulle hoe interessant, so word 'n ouer digter nie gered nie. Dit doen jy deur sy "vreemdheid" of "ouderwetsheid" te beklemtoon, deur te wys op dit wat essensieel Leipoldt is, deur sy signatuur in sy werk bloot te lê - as jy kan. In dié verband skryf Culler (1977, p. 262): "It is precisely the traditional work, the work that could not be written today, that may most benefit from criticism, and the criticism which encounters the greatest success is one which attends to its strangeness, awakening in it a drama whose actors are all those assumptions and operations which make the text the work of another period" (my kursief).

“Assumptions and operations" kan ons vir ons doel hier vertaal met "gespreksvoorwaardes".

Louw (1972, p. 53) het al vasgestel dat die "sentrale beginsel" van Leipoldt se werk " 'n oormeesterende gevoel vir die vreemde" is. Hy skryf: "Die vreemde is die kern van sy wêreldbeeld. Dit is die verwondering van die kind oor die wêreld wat hom omring: 'n gedurige verbasing oor die vreemdheid van wat vir ander reeds alledaags lyk, 'n verbasing oor die onbekende wat telkens weer ontdek word, en 'n uitreik na alles wat vreemd en nuut en ver is" (sy kursief).

Anders gestel: hierdie vreemdheid is 'n sterk besef van die uniekheid van alle dinge. Dit verklaar die groot liefde vir die mooi, magiese naam wat ons in Leipoldt se poësie aantref. Leipoldt self het hierdie beginsel geformuleer in die gedig wat Mulder (1942, p. 25) bestempel het as "Leipoldt se eintlike indiwidualistiese geloofsbelydenis". Dit is die gedig "By die vlei" (Leipoldt, 1980, p. 166, voortaan aangehaal as VG):

Soek jy na suiwere waarheid, O Siel wat versteen staan? Wat is die waarheid wat suiwer as waarheid kan geld?

Dit: dat jy staan, skoon jy enkel apart en alleen staan.

Dit: dat jy is, en rondom jou die nag en die veld

(Mulder se kursief). 
Dit is nie net ' $n$ individualisme van die digter of die mens nie; dit kan veralgemeen word na al die dinge wat in Leipoldt se poësie voorkom. Die gevolg van hierdie verbasing oor die alledaagse is dat Leipoldt se poësie so opgaan in die besonderhede dat die groot verband, die geheelbeeld verdwyn. Cloete het uitvoerig op hierdie saak ingegaan. Die slotsom van sy artikel oor "Leipoldt as digter van besonderhede" is: "By Leipoldt ontbreek die groot verband, of verbande heeltemal" (Cloete, 1966, p. 55). Ek sal later 'n bietjie met hierdie slotsom polemiseer. Die uniekheid van die enkele ding slaan ook uit in die sinsbou van Leipoldt se gedigte, aldus Merwe Scholtz. Hy sê Leipoldt se poësie berus op 'n "tekskonvensie wat ... die verskillende gegewens een vir een, in hulle afsonderlikheid te kenne wil gee" (Scholtz, 1966, p. 144). Ook hieruit blyk die belang van die unieke ding in Leipoldt se poësie.

Die beginsel van die vreemde hou ook in dat alledaagse dinge in Leipoldt se poësie vreemd gemaak word deur hulle te ondervra of gesprekke met hulle aan te knoop. Dit gee aanleiding tot 'n soort ontologiese verbasing. Klokkies, 'n sekretarisvoèl, 'n ou boek, 'n kriekie, 'n apie, 'n seepkissie word ondervra of in 'n gesprek betrek. Op die manier het Leipoldt eintlik vir hom 'n reeks vlugvorme geskep waarin hy aan die gevaar van 'n te persoonlike poësie kon ontsnap, "dramatiese ekwivalente" vir sy emosie kon skep.

Lindenberg (1962) het ook al op vreemdheid in Leipoldt se poësie gewys. Hy praat van "die duister Leipoldt", en dit na aanleiding van een van Leipoldt se bekendste gediggies, “Kom gee vir my polfyntjie” (VG 286).

Kom gee vir my polfyntjie,

Dit maak nie saak nie wat,

Die kleinste, nietigste lyntjie

Waardeer ek as 'n skat.

Koop waar jy wil, by smouse,

Penswinkeltjies, net wat

Jy kry in Krismiskouse -

Dit bly vir my 'n skat.

Net iets wat jy as joue Betrag het, gee my dit E.k neem dit aan as goue Gesteente tot besit.

En as jy cenmaal sterwe, Dan pryk dit nog by my, 
Gegee meer as geërwe,

As liefdeblyk gekry.

Lindenberg breek deur die outomatisme deur te vra: wat beteken polfyntjie? Dis eintlik die eerste vraag wat 'n leser homself behoort af te vra. Dit het dan niks met die hak van skoen te doen nie en dis ook nie 'n watsim of 'n hoesim nie; Linden berg voer dit terug na filippientjie of filippyntjie, oorspronklik 'n amandel met 'n dubbele pit wat tussen mans en dames gebruik is met pandspeletjies. Daarom noem Lindenberg (1962, p. 51) hierdie gedig “'n bekoorlike en sjarmante pleidooi om 'n konkrete voorwerp as bewys van liefde". Polfyntjie beteken dus "aandenkinkie, liefdespandjie".

Maar dis nie al nie. Boshoff en Nienaber (1967, p. 511) omskryf polfyntjie as 'n bepaalde soort koekie, 'n nooientjie, 'n pand by pandspeletjies of as 'n aandenking. In die derde geval is die verband met filippientjie, wat Lindenberg trouens terug voer na Duits Vielliebchen, seker onmiskenbaar, al ag Boshoff-hulle dit bloot "moontlik". Maar hoe gemaak met die koekie? Bosman-hulle voer dit terug na pol, polle, Nederlands vir 'n klein, harde koekie. Of berus hierdie betekenis van polfyntjie bloot maar op Leipoldt se eie boek, Polfyntjies vir die proe? - 'n boek waarin hy, na my wete, die woord nêrens gebruik nie; hy skryf daarin trouens nêrens eers oor koekies nie.

Gelukkig hoef die leser nie te vreeslik te wonder oor die betekenis van polfyntjie nie. Dit is hoogstens 'n onbekende faktor, 'n $X$, aan die begin van die gedig waardeur die leser se aandag geboei word. Die gedig het, soos Elize Lindes gesê het, sy eie inligtingstelsel(Lindes, 1956, p. 100). Die hele gediggie word eintlik daaraan gewy om die woord polfyntjie te omskryf. En wat my interesseer, is hóé dit gedoen word. Die gedig noem 'n aantal fasette van die polfyntjie op: dit kan sommer enigiets wees, dis klein en nietig, en die klankherhaling onderskryf hierdie nietigheid. Die $/ y /$, die klank van polfyntjie en van klein, "beklemtoon aanvanklik die nietigheid van die gevraagde voorwerp" (Lindenberg 1962: 49). Die polfyntjie kan verder op enige plek gekoop word: dis iets grilligs of irrasioneels. Jy kan dit selfs in Krismiskouse kry. Juis die grilligheid daarvan word nader bepaal deur die ongewone, grillige rym van smouse met Krismiskouse. Twee gans uiteenlopende wêrelde, die wêrelde van Mordechai en Christus, word hier in die klank saamgetrek. 'n Polfyntjie is ook 'n skat - iets kosbaars, maar ook iets wat van die gewer 'n skat maak (vgl. Lindenberg, 1962, 50). Die voorwerp wat egter die waarskynlikste aan hierdie beskrywing sal beantwoord, word in die gedig aangedui met die woord lyntjie - met 'n y. Dit bied verskeie moontlikhede: toutjie, versreëltjie 
maar die ding wat mens wel by smouse of penswinkeltjies kan gaan koop, is ' $n$ lintjie - verkleinwoord van lint, aldus Lindeberg (1962, p. 51).

Lindenberg (1962, p. 49) sê die /y/ kry later "'n meer nadruklike klank". Die nietige voorwerpie word in die tweede strofe iets besonder eie aan die geliefde en die spreker in die gedig begin dit ervaar as iets groots en belangriks - goue gesteente, iets wat kan pryk, uiteindelik 'n liefdeblyk. Hierdie liefdeblyk is nie geërwe nie, maar gegee en gekry. Mens kan se Leipoldt, wat dikwels so slordig met sy rymwoorde werk, het hier per ongeluk die regte een gekry om die spontaneiteit, willekeurigheid en irrasionaliteit van die aandenkinkie mee uit te druk. Met dit alles is polfyntjie eintlik ' $n$ woord met 'n veel ryker betekenis as bloot "liefdesblyk"; die vlag dek nie die lading nie. Polfyntjie bly vir die leser raaiselagtig, prikkelend.

U sien dus, dames en here, Leipoldt gee nie vir ons 'n reeks dinge wat gelyk staan met die polfyntjie nie, m.a.w. nie 'n reeks metafore om die aard daarvan te verduidelik nie. Hy gee 'n reeks eienskappe, 'n reeks fasette van die polfyntjie. Elkeen vorm 'n deel van die groot, saamgestelde betekenis van polfyntjie. Daar is dus 'n metonimiese verband tussen polfyntjie en sy verskillende betekeniskomponente. Metonimia kan gedefinieer word as 'n verband tussen twee dinge wat nie op ooreenkoms of kontras berus nie.

Hierdie siening berus op 'n teorie van Jakobson (1975, p. 69 - 96). Volgens hom kom taal tot stand deur twee ordeningsbeginsels, naamlik kombinasie en seleksie. 'n Spreker kombineer foneme tot woorde, woorde tot sinne, sinne tot paragrawe, ens. Terselfdertyd selekteer hy die elemente wat hy kombineer uit die versameling moontlike alternatiewe wat die taal hom bied. Dié twee prosesse kry omtrent ewe veel klem, maar elke spreker neig tog op grond van persoonlikheid en kultuur ietwat na een van dié twee pole. As een persoon 'n stimuluswoord soos hoed gegee word, sal hy bv. antwoord met hoofdeksel, sal hy m.a.w. antwoord met 'n ekwivalente term geselekteer uit die taalskat. 'n Ander persoon sal weer sê My pa dra nog hoed, d.w.s. die gegewe woord met ander element kombineer tot 'n sin. Skrywers kan op grond hiervan ingedeel word in diegene by wie seleksie oorheers en diegene by wie kombinasie oorheers (Ohmann, 1970, p. 210). Dit lyk vir my of kombinasie by leipoldt oorheers of sterker ontwikkel is as seleksie. Ily is dus nie soseer ingestel op ooreenkomste tussen die uiteenlopende dinge wat hy byvoorbeeld in "Kom gec vir my pollyntjie" noem nie, maar op die geheel wat uit die verskillende onderdele opgebou word. Ily moet, volgens hierdie teoric ook 'n voorkeur toon vir metonimia i.p.v. metafoor, want matafoor en metonimia is vir 
Jakobson onderskeidelik die mees gekonsentreerde uitings van die twee pole seleksie en kombinasie. Daarom kry 'n mens, volgens hom, metafore veral in poësie en metonimia veral in prosa, meer spesifiek realistiese prosa. Met metonimia het ons daarom miskien uitgekom by 'n baie basiese strategie of "operation" in Leipoldt se werk. Voordat ek hierdie verskynsel in drie van sy gedigte nagaan, gaan ek eers 'n paar ander gespreksvoorwaardes vir Leipoldt se poësie noem soos dit na vore kom in 'n klompie kunsteoretiese gediggies wat onder die sg. slampamperliedjies tel (vgl. Strydom, 1969). Niemand weet juis mooi wat 'n slampamperliedjie nou eintlik is nie, maar dit is so eie aan Leipoldt soos polfyntjie. Die slampamperliedjies is dan ook Leipoldt se mees kenmerkende bydrae tot ons letterkunde.

'n Voorwaarde of uitgangspunt vir Leipoldt se poësie is blykbaar verbeelding. Leipoldt se definisie daarvan in die slampamperliedjie "As ek van verbeelding praat" (VG, p. 194) bevat 'n baie sterk irrasionele element, nes "Kom gee vir my polfyntjie":

As ek van verbeelding praat,

Dan glo ek maar ek preek van 'n paradys

Waarheen net 'n engel te perd kan reis,

Want daar is geen gids wat die weg kan wys .

En hoe vroeg jy opsaal, jy kom te laat.

Hierdie paradys is met die verstand heeltemal onbereikbaar, en hou daarom vir die moderne leser heelwat bekoring in. Die beeld van die engel te perd is skynbaar aan 'n resep ontleen. Later vanaand sal $u$ vals engele-te-perd te ete kry, gebaseer op die resep van Leipoldt in Kos vir die kenner. Die ware jakob het oesters in plaas van lewer in, en dan smaak dit seker, soos die Hollanders sê, "of een engeltje op je tong piest". Dis in so 'n verbinding van die kookkuns en die digkuns dat ons die genialiteit van Leipoldt se verbeelding erken.

Verveelding hou verband met ander gespreksvoorwaardes wat o.m. blyk uit die slampamperliedjie "Jy sê vir my: 'Ou boetjie, wat moveer jou' " (VG. p. 52):

Nou goed, ou boet; ek skrywe nie vir jou nie.

Die windswael sing - nou, waarvoor moet hy sing?

Vir jou en my? Nee, wragtie, vir homselwe -

Net om hy iets moet se - iets, iets moet bring! 
Soos die windswael sing, so skryf die digter versies. Let op hoe die singery nageboots word deur die herhaling van iets. Albei hierdie dinge is dinge wat moet; nie ter wille van die gehoor nie, maar vir die spreker of sanger self, uit 'n soort innerlike noodwendigheid. Dis bowendien by uitstek iets natuurliks, spontaans en naiefs. Op baie plekke in Leipoldt se poësie kry mens trouens hierdie klem op die spontane, natuurlike uiting. So iets is versies mak ook (vgl. Dekker, 1934, p. 97 - 8).

Leipoldt praat hier effens geringskattend van "versies". Sy geringskatting van sy werk is legendaries. Sy slordigheid ook. Oor die finale versorging van sy werk het hy hom nooit juis veel bekommer nie (vgl. Kannemeyer, 1977). Toe 'n uitgewer hom daarop gewys het dat een van sy sonnette net dertien reëls het, het hy glo gesê die teksversorger moet maar self 'n veertiende reël byskryf. Sy gepubliseerde gedigte is daarom ook vol slordighede soos anglisismes, lomp sinswendings, swak woordkeuses. Soms gebruik hy sommer die eerste die beste rymwoord. Sy gedigte is vol rymdwang, stoplappe en oormatige taalverwringing. Dit lyk soms na volslae onmag. Sekere lastige gewoontes soos die gee my- of daar... waar-mode en die woordjie orals kom baie dikwels in sy poësie voor (vgl. Louw, 1958). Al hierdie dinge kan eintlik toegeskryf word aan sy opvatting dat poësie spontaan en natuurlik moet wees.

In 'n sekere $\sin$ is hierdie geringskatting van sy poësie maar skyn. Dit is m.i. verge. lykbaar met wat ons ook by ons jonger digters kry, nl. 'n neiging om die waarde van hulle werk en van die poësie in die algemeen te relativeer, dit nie ernstig op te neem nie (Cloete, 1980, p. 116-7).

"Op my ou ramkietjie" (VG. p. 196) kan ook beskou word as 'n kunsteoretiese gedig. Hier tref ons 'n tipies boheemse digtersfiguur aan. Op sy eensnarige, volkse instrument maak hy liedjies wat vir die mense onverstaanbaar is. En dit boonop nog in die maanskyn. G'n wonder die mense sê hy's halfpad mal of selfs heeltemal mal nie. Dit dui 'n derde gespreksvoorwaarde aan, naamlik die besetenheid van die digter, die furor poeticus wat al sedert die tyd van Plato aan die digter toegeskryf word. Volgens hierdie opvatting moet die digter eers deur die een of ander goddelike wese ingeblaas of besete wees voordat hy kan skep (Shipley, 1972, p. 227-229). In sy artikel oor Leipoldt as digter, wat 'n mens soms nogal baie aan Kloos se beroemde Inleiding van 1881 herinner, skryf Dekker ook oor hierdie aspek van Leipoldt se poësie. Hy noem dit Leipoldt se hartstog (Dekker, 1934, p. 92). Maar in die geval van Leipoldt, nes by enige ander digter, is dit goed om die Franse digter Paul Valéry se woorde in gedagte te hou: "(The poet) is no longer 
the dishevelled madman who writes a whole poem in the course of one feverish night; he is a cool scientist, almost an algebraist, in the service of a subtle dreamer" (Valéry, 1958, p. 315).

'n Laaste gespreksvoorwaarde vir Leipoldt se poësie is dat hy gewone alledaagse praat-Afrikaans in sy gedigte gebruik. Verwey $(1921$, p. 101) het dit so gestel: "Deze poëzie is een bloem van spraak, zoals zij in zijn meest bewogen dagen, uit het hart en op die lippen van een dichter ontloken is". Van Wyk Louw skryf weer oor "die innige verhewigde praat wat Leipoldt se krag is" (Louw, 1972, p. 70). Ook dit is 'n spontane en natuurlike uiting van die mens; so natuurlik soos die windswael se sing.

Een van Leipoldt se bekendste kunsteoretiese gediggies is "Ek sing van die wind" (VG. p. 53):

Ek sing van die wind wat te keer gaan;

Ek sing van die reën wat daar val;

Ek sing van ons vaal ou Karooland;

Van blomme wat bloei by die wal

Van water wat bruis oor die klippe;

Van duikers wat draf oor die veld;

Van voëls wat daar sing in die bossies -

Maar nooit nie, nee nooit nie, van geld!

Vir my sing maar liewers van blomme;

Van al wat die vlei laat verkleur;

Van al wat die sonskyn laat spartel;

Van voorjaar en najaar se geur;

Vir my sing maar liefs van die rvater;

Van duikers wat draf oor die veld;

Van rotse en branders en wolke.

Maar nooit nie, nee nooit nie, van geld!

Hier gee die spreker vir ons 'n hele reeks dinge waaroor hy sing. Dan rond hy die gedig af met dit waaroor hy nié sing nie, nl. geld - in skerp teenstelling net die voorafgaande. Al hierdie dinge - wind, reën, ons vaal ou Karooland, blomme, water, duikers, voëls - word geplaas in parallelle sinne: oor en oor word dieselfde sintaktiese patroontjie herhaal: 
Ek sing van die wind wat te keer gaan

Ek sing van die reën wat daar val

(E.k sing) van blomme wat bloei by die wal

(Fk sing) van water wat bruis oor die klippe.

Sommige verse het nou wel 'n daar by - "Ek sing van die reën wat daar val" maar as ' $n$ mens die gedig skandeer, blyk dat die daar 'n blote stoplap of metriese vulsel is: Dis bloot daar om die starre metriese patroontjie vol te maak en die verse dus metries ook volkome ekwivalent te maak. Sintakties en metries gesproke is daar dus 'n sterk verband tussen die verskillende dinge in die gedig.

'n Mens sou nou ook 'n sterk semantiese verband verwag; maar dit is nie die geval nie. Elkeen van dié dinge is eiesoortig, en hulle eiesoortigheid word beklemtoon deur dat elkeen gekoppel word aan sy eie, spesifieke natuurlike handeling: die wind gaan te keer, reën val, blomme bloei by die wal, water bruis oor die klippe, duikers draf oor die vlei, voëls sing in die bossies. Elke eiesoortige handeling vind ook op 'n spesifieke plek plaas. Selfs Karooland kry drie sterk verbesonderende bepalings by: "ons vaal ou Karooland". Daar is eintlik geen verband tussen dié dinge nie, behalwe dat hulle almal natuurdinge is wat elk sy eie kenmerkende natuurhandeling uitvoer. En hierdie verbandloosheid dien juis om die spontaneiteit van sing te illustreer. Die eiesoortige handelings kan ook dien as tekens van hierdie verskynsels se volledige' natuurlewe, maar jy kan hulle ook gaan lees as 'n lysie landskapselemente. Dan word daar 'n hele landskap met naam en al geskep, polsend van lewe: ons vaal ou Karooland met sy wind, reën, blomme, water, veld, duikers en voëls in die bossies. So gesien is 'n sinsstuk soos "by die wal" bloot 'n ander (miskien onbeholpe) manier om te sê: daar is ' $n$ wal in hierdie landskap. Daar is dus ook klippe, bossies, veld in hierdie landskap. "Er staat niet wat er staat". So word die landskap van "ons vaal ou Karooland" metonimies opgebou. Tog dra die parallelisme in die sinsbou baie daartoe by dat ons die gedig (en die landskap) as 'n eenheid ervaar.

'n Ander ewe bekende gedig van Leipoldt, "Oktobermaand" (VG, p. 11-2) is ook metonimies opgebou. Nes in "Kom gee vir my polfyntie" word die groot geheel, die samevattende term aan die begin gegee: "Dit is aie maand Oktober". Maar laat ons cerder stilstaan by 'n ander bekende natuurgedig van Leipoldt, nl. " 'n Handvol gruis uit die Hantam" (VG, p. 193).

'n Handvol gruis uit die Hantam -

My liewe lekker Hantam-wyk! 
'n Handvol gruis en gedroogde blare, Waboom-blare, ghnarrabos-blare!

Arm was ek gister, en nou is ek ryk.

Arm in herinnering, arm in verbeelding, Arm in onthou van die vroeër jare Deurgebring in die Hantam-wyk. 'n Handvol gras en gedroogde blare Maak my wat arm was, koning-ryk.

Ryk in herinnering, ryk in verbeelding, Ryk in onthou van die vroeër tyd Toe die Hantam-wêreld al die wêreld Vir my was in die vroeër tyd.

'n Handvol gruis en gedroogde blare Vertel so veel van die wonderjare In my liewe lekker Hantam-wyk Waboom-blare, ghnarrabos-blare Arm eergister en nou skatryk!

Weer nes in 'Kom gee vir my polfyntjie' word die betekenis van die eerste reel in die loop van die gedig uitgebou, metonimies, stap vir stap. Die tweede vers, "My liewe, lekker Hantam-wyk", is al 'n ontwikkeling van Hantam. Hier word 'n besonder innige emosie aan Hantam verbind. Die volgende twee verse gee vir ons meer besonderhede oor die handvol gruis: eers hoor ons dat dit ook uit gedroogde blare bestaan en dan presies watter soort blare: "Waboom-blare en ghnarrabosblare". Uit hierdie lyflike ervaring van die materie, wat tegelyk ook inkantasie met die mooi of unieke name self is, ontwikkel die digter in die volgende vers 'n formule om sy emosies mee vas te vat: "Arm was ek gister, en nou is ek ryk". In die eerste strofe is die temavers (die eerste vers) dan nou ontwikkel tot drie subtemas: die aard van die handvol gruis, die emosionele betekenis van Hantam en die tema van arm en ryk.

Die volgende twee strofes is nou weer 'n verdere ontwikkeling van hierdie drie subtemas. Daardeur kry die gedig 'n soort musikale scruktuur. In strofe 2 word die arm-tema eers verder ontwikkel: daar word verduidelik hoekom die spreker arm is: Hy is "arm in herinnering, arm in verbeelding, arm in onthou van die vroeër jare". Die armoede het te doen met 'n gebrek aan ware, volle lewe. Die volgende vers verbind Hantam aan 'n vierde subtema: die vroeër jare. So word die emosione- 
le betekenis van Hantam verder verduidelik. Ook word 'n nuwe element ingevoer wat later weer ontwikkel sal word. Nadat die omskrywing van die handvol gruis verder gevoer is tot "' $n$ handvol gras en gedroogde blare", sluit die strofe af met die teenstelling tussen arm en ryk 'n stappie verder gevoer: "Maak my, wat arm was, koning-ryk".

In strofe 3 word die ryk-tema nes die arm-tema in strofe 2 ontwikkel. So ryk is die spreker nou dat die Hantam-tema tot vier verse uitgebrei word:

Toe die Hantam-wêreld al die wêreld

Vir my was in die vroeër tyd

En:

Vertel so veel van die wonderjare

In my liewe lekker Hantam-wyk.

Die rykdom kan hier dus amper gemeet word aan die aantal verse. En in die konteks van dié vier verse kry ook die sleutelvers, “' 'n handvol gruis en gedroogde blare")' $n$ ander betekenis. Dit word nou as 't ware 'n tolk - dit vertel nou, dit kry nou stem. Die gedig eindig weer met die kontras tussen arm en ryk, maar weer 'n stappie verder gevoer: "Arm eergister en nou skatryk". Die afstand tussen dié twee toestande is nou veel groter as voorheen. $R y k$ is eers ontwikkel tot koning-ryk en uiteindelik tot skatryk; nes vroeër jare ontwikkel is tot vroeér tyd en uiteindelik tot wonderjare. Parallel daarmee loop ook 'n uitgroeiproses in die begrip Hantam self: vanaf bloot net Hantam, na Hantam-wyk en uiteindelik Hantam-wêreld. Aan die einde word daar teruggekeer na Hantam-wyk en die gedig op 'n bevredigende manier voltooi deur twee verse uit die eerste strofe te herhaal:

In my liewe lekker Hantam-wyk .

Waboom-blare, ghnarrabos-blare -

llierdie presiese, noukeurige ontwikkeling van die temas wat die eerste vers al vir ons ingee, maak tot leuen enige bewering dat Leipoldt nie 'n vormbewuste digter was nie. Hy was miskien 'n lui digter, of 'n digter vir wie die volmaakte vorm meestal ontwyk het, maar hier is hy "a cool scientist" by uitstek. Daarom kan ons hierdie gedig in sy geraffineerde gebruik van herhaling en teenstelling vergelyk met Egidius. 
Nog 'n belangrike bydrae van Leipoldt tot ons letterkunde is sy oorlogsgedigte. "Toe dit gelvk het asof ons as volk finaal verneder en reddeloos verlore was", skryf Louw (1972, p. 84), "toe het Leipoldt gepraat, woorde gegee aan ons smart". Vandag kan ons die oorlogsgedigte gaan lees as 'n aanklag teen alle vorms van onmenslikheid, wreedheid en geweld. Hulle bly aktueel vir ons tyd. Leipoldt het ook gedigte ocr die Tweede Wêreldoorlog geskryf, maar dit is in sy gedigte geinspireer deur die Tweede Vryheidsoorlog dat hy gestaltes geskep het wat vandag nog onvergeetlik bly. Oom Gert van "Oom Gert vertel" is die heel eerste oortuigende karakter in die Afrikaanse letterkunde. En, hoewel minder groot, is die gestalte van die jong, verbitterde Afrikaner in Londen na die vredesluiting wat ons uit "Vrede-aand" leer ken, nie minder boeiend nie. Verbitterd, teleurgesteld, halfdronk.kan hy net sarkasties vra:

Wat is ons land teenoor die aandeelmark?

Wat is 'n kanarievoël teenoor 'n vark?

'n Lelieblom teenoor 'n stronk tabak?

Ons nasie, wat so wild was, is nou mak

En kan getrein word soos ' $n$ jong bob'jaan.

Die gebruik van die Engelse woord getrein is hier besonder ironies, want dit suggereer dat "ons nasie" nou volkome aan die wil van die Engelse onderwerp is. Die jong Afrikaner vind egter sy troos in 'n bottel soetwyn en in die gedagte aan die vrou se heldemoed tydens die oorlog, sodat die gedig uitloop op 'n pleidooi vir vroueregte wat verrassend modern klink:

Dis vrede, ja! Wat sal ons nou begaan?

Sal ons die vrou daar binne weer laat staan

Om kos te kook, te braai, te stoof, te smoor?

Nie meer haar steun verlang nie? nie meer hoor

Haar stem wat in die onweer helder klink?

Sal ons haar siel laat roes?

Hier is Leipoldt die koskenner aan die woord. Maar sou dit te vergesog wees um te beweer dat dit is omdat Leipoldt hierdie gedig geskryf het dat meer vroue vandag in Suid-Afrika werk as bv. in Nederland?

"Aan 'n seepkissie" (VG, p. 30), die oorlogsgedig wat u vanaand al gehoor het, is eienaardig in dié opsig dat die spreker in dić gedig die seepkissie gebruik as 'n soort "objective correlative" of "dramatiese ekwivalent" vir die pyn van die oorlog. 
Die gedig ontwikkel ook metonimies. Die werklike betekenis van die seepkissie kom eers tot stand nadat die verhaaltjie van Klein Jannie en sy skielike dood vertel is. Tussendeur word die seepkissie aanhoudend aangespreek. Hier is daar ook sprake van verwondering oor die seepkissie en wat uiteindelik van hom word, maar dis ' $n$ fel ironiese verwondering, gelaai met verontwaardiging en bitterheid. Die eintlike gruwel waaroor die spreker in die gedig hom verwonder, is egter die onvermydelikheid waarmee hierdie verhaaltjie afloop. Dié gruwel lê al opgesluit in die eerste twee verse, maar dis eers na afloop van die verhaaltjie dat die seepkissie sy werklik pregnante betekenis kry:

Hulle het jou in Eng'land gemaak, seepkissie,

Om hier vir ons kinders as doodkis te dien;

Hulle het vir jou lykies gevinde, scepkissie,

En ek het jou selwe as doodkis gesien.

Dit is asof die Engelse opsetlik seepkissies vervaardig het wat bestem is of ontwerp is as doodkissies vir ons kinders. En dan soek hulle opsetlik - en vind ook! lykies vir dié seepkissies. Wat dit nog meer diabolies maak, is dat die kinders niksvermoedend met hierdie seepkissies speel! So word die seepkissie 'n diaboliese maaksel van die Engelse om ons kinders selfs ook nog die laaste eer van 'n waardige begrafnis te ontsê. Die seepkissie groei uit tot beeld van die hele Engelse volk en hulle kultuur. Dit word 'n skrikwekkende beeld van "man's inhumanity to man".

Ten slotte: 'n Skrywer sal in sy honderdste geboortejaar seker verkies dat 'n mens nic lofredes op hom sing nie, maar eerder sy werk weer goed gaan lees. Miskien kom ons 'n bietjie verder met Leipoldt of kan ons 'n bietjie meer waarde aan hom heg as ons hom gaan lees as 'n realistiese digter wie se gedigte metonimies funksioneer en nie metafories nie. Dan gee ons sy werk dalk meer krediet vir gaafheid en heelheid en hou ook meer krediet vir sy strukturerende vermoë.

\section{BIBLIOGRAFIE}

BOSHOFF, S.P.E. en NIENABER, G.S. 1967. Afrikaanse etimologiě̌. Pretoria: Suid-Afrikaanse Akademie vir Wetenskap en Kuns.

BUDDINGH, C. 1977. Lexicon der poezie. Amsterdam: Arbeiderspers.

CLOETE, T.T. 1966. Leipoldt as digter van besonderhede. (In: SMAL swaard en blink. 1966. Pretoria: Academica). 
CLOETE, T.T. 1980. Die Afrikaanse literatuur sedert sestig. Kaapstad: Nasou.

CULLER, J. 1977. Structuralist poetics. London: Routledge \& Kegan Paul.

DEKKER, G, 1934. Leipoldt as digter. (In: Sy Causerie en kritiek. Pretoria: Van Schaik).

F REEMAN, D.C. 1970. Linguistics and literary style. New York: Holt, Rinehart and Winston.

JAKOBSON, R. 1975. Two aspects of language and two types of aphasic disturbances. (In: Jakobson, R. en Halle, M. 1975. Fundamentals of language. The Hague: Mouton).

KANNEMEYER, J.S. 1977. Teksversorging by C. Louis Leipoldt. (In: Sy Konfrontasies. Pretoria: Academica).

LEIPOLDT, C.F.L. 1980. Versamelde gedigte. Kaapstad: Tafelberg.

LEIPOLDT, C.F.L. 1933. Kos vir die kenner. Kaapstad: Nasionale Pers.

LINDBERG, E. 1962. Die duister Leipoldt. Standpunte, 40 (4-5) Apr - Jun 1962: 48-55.

LINDES, E. 1956. Veelheid en binding. Amsterdam: Noord-Hollandsche U.M.

LOUW, N.P. VAN WYK. 1972. Opstelle oor ons ouer digters. Kaapstad: Iluman en Rousseau.

LOUW, W.E.G. 1958. Vormprobleme by Leipoldt. (In: Sy Ou wyn van vreugde. Kaapstad: Balkema).

MULDER, H.A. 1942. Twee wêrelde. Pretoria: Van Schaik.

OHMANN, R. 1970. Modes of order. (In: Freeman, D.C. 1970. Linguistics and literary style. New York: Holt, Rinehart and Winston: $209 \cdot 242)$.

SCHOLTZ, M. 1966. Bydrae tot 'n Leipoldt-topografie. (In: SMAL, swaard en blink. Pretoria: Academia). 
SHIPLEY, J.T. 1972. Dictionary of world literature. Totowa, NJ.: Littlefield, Adams \& Co.

STRYDOM, L. 1969. 'n Studie van C. Louis Leipoldt se slampamperliedjies. M.A.-verhandeling, Stellenbosch.

VALéRY, P. 1958. On literary technique. (In: $S_{y}$ The art of poetry. London: Routledge \& Kegan Paul).

VERWEY, A. 1921. De poëzie van Zuid-Afrika. (In: Sy Proza I. Amsterdam: Van Holkema \& Warendorf). 